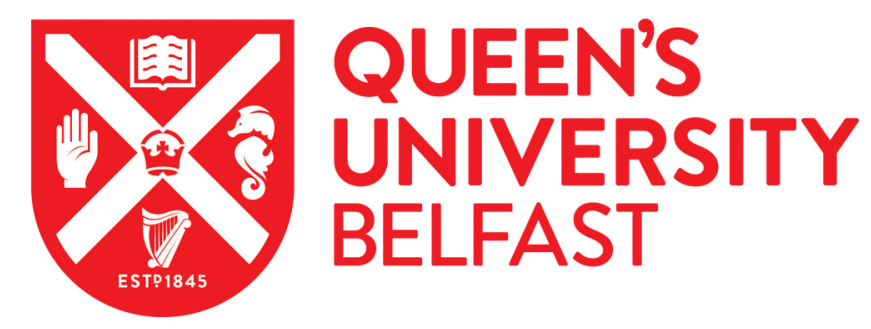

\title{
Protocol: An efficacy randomized controlled trial of a Vocabulary program in primary schools
}

Cockerill, M., Thurston, A., \& Taylor, A. (2020). Protocol: An efficacy randomized controlled trial of a Vocabulary program in primary schools. International Journal of Educational Research, [101511].

https://doi.org/10.1016/j.ijer.2019.101511

\section{Published in:}

International Journal of Educational Research

\section{Document Version:}

Peer reviewed version

\section{Queen's University Belfast - Research Portal:}

Link to publication record in Queen's University Belfast Research Portal

\section{Publisher rights}

(c) 2019 Elsevier Ltd.

This manuscript version is made available under the CC-BY-NC-ND 4.0 license http://creativecommons.org/licenses/by-nc-nd/4.0/,which permits distribution and reproduction for non-commercial purposes, provided the author and source are cited.

\section{General rights}

Copyright for the publications made accessible via the Queen's University Belfast Research Portal is retained by the author(s) and / or other copyright owners and it is a condition of accessing these publications that users recognise and abide by the legal requirements associated with these rights.

Take down policy

The Research Portal is Queen's institutional repository that provides access to Queen's research output. Every effort has been made to ensure that content in the Research Portal does not infringe any person's rights, or applicable UK laws. If you discover content in the Research Portal that you believe breaches copyright or violates any law, please contact openaccess@qub.ac.uk. 


\title{
Protocol: An efficacy randomized controlled trial of a Vocabulary program in primary schools
}

\begin{abstract}
This paper presents the research protocol for an efficacy randomized controlled trial of a vocabulary program in primary schools. The program is a workforce development program that supports teachers and teaching assistants develop and deliver targeted vocabulary instruction to children aged 7-10. The protocol outlines a research design to assess whether the program delivered over approximately 20 weeks improves reading outcomes, in a sample of 101 children from 7 schools in three English districts with high socio-economic disadvantage. The outcome measure is a reading standardized test. A process evaluation will measure fidelity and potential for scaleup.
\end{abstract}

\section{Key Words}

Vocabulary; Comprehension; Primary School; Teacher Training; Literacy; RCT

\section{Background}

The consequences of a limited vocabulary are apparent across the education system, impacting on children's attainment at all stages. For example, high performing children on entry to school have an average estimated vocabulary size of 7100 words, while relatively poor performing students know around 3000 words (Biemiller, 2003). These gaps do not narrow; poorer performing students acquire a new word a day compared to three a day acquired by higher performing students. By the age of 16 the vocabulary gaps identified among 6-year-olds account for around a third of the variance in reading comprehension (Cunningham and Stanovich, 1997).

Poor vocabulary knowledge is identified as a major cause of academic failure among socio-economically disadvantaged children (Becker, 1977). Children from a low socioeconomic background typically have a smaller vocabulary than children from higher socio-economic backgrounds, and the gap widens as children get older (Beals, 1997; Waldfogel and Washbrook, 2010). Yet research indicates that the benefits of a rich vocabulary for young children accrue rapidly as they become readers (Apthorp, Randel, Cherasaro, Clark, McKeown, and Beck, 2012) and a strong vocabulary is known to be a good predictor of reading success (Biemiller, 2003, National Reading Panel, 2000), particularly for reading comprehension (Becker, 1977). Disadvantaged students in particular show declining reading comprehension as their narrow vocabulary limits what they can understand from texts (Chall, Jacobs and Baldwin, 1990). In turn, being unable to read more sophisticated texts means that students have fewer opportunities to extend their vocabulary (Fisher and Blachnowicz, 2005).

Observational research suggests that very little intentional vocabulary instruction takes place in the primary grades (Wanzek, 2014). Nevertheless, specific vocabulary instruction can have a positive impact (Beck and McKeown, 2007), specifically on children's reading comprehension. There is also broad consensus that vocabulary can 
be taught effectively at school (Duke and Moses, 2003). Stahl and Fairbanks (1986) summarize results from 41 studies, reporting an average positive effect size of 0.91 , an effect size which would theoretically raise the comprehension of an average child from the $50^{\text {th }}$ percentile to the $83^{\text {rd }}$ percentile. More recently, meta-analyses confirm the effectiveness of vocabulary instruction for improving vocabulary ability (ES +0.29 to 1.21 ) and reading comprehension (ES+0.10 to 0.50) (Elleman, Lindo, Morphy \& Compton, 2009; Marulis \& Newman, 2010). With children's vocabulary knowledge being an important factor for effective reading comprehension, vocabulary training throughout the primary school stage should benefit children to build a large sight vocabulary allowing them to automatically access word meanings (Verhoeven, van Leeuwe, and Vermeer, 2011).

The importance of vocabulary to learning is identified in the UK's 2014 National Curriculum program of study for English. It states: Students' acquisition and command of vocabulary are key to their learning and progress across the whole curriculum. Teachers should therefore: develop vocabulary actively, building systematically on students' current knowledge; increase students' store of words in general; and, make links between known and new vocabulary and discuss the shades of meaning in similar words. This echoes Stahl and Kapinus (2001) research who suggest a range of approaches used together in vocabulary instruction is most effective. These include: helping children gain ownership of words (being able to use or think about a word in a variety of different ways); providing multiple exposures through rich and varied activities to meaningful information about the word; and, instruction which includes both definitional and contextual information about each word's meaning and which involves children more actively in word learning.

The following protocol describes a Medical Research Council Level 2 efficacy/exploratory randomized controlled trial (Medical Research Council, 2000) study aimed at evaluating the impact of a new vocabulary program on students' attainment in reading on a targeted basis in primary schools in England. This study has been funded by the Education Endowment Foundation North East Primary Literacy Campaign in the UK, as part of the Transforming Tees Advocacy program.

\section{The intervention}

The Fischer Family Trust Literacy (FFTL) vocabulary program was developed in 2018. The intervention is delivered by practising teachers and teaching assistants, in mainstream UK settings for students aged $7-8$ years and $9-10$ years, and workforce development is an essential part of the program. All teachers and teaching assistants involved in delivering the program receive one and half days' off site training from FFTL, who also provide on-site advisory support during delivery of the program (half day in schools).

The training covers the knowledge, skills and understanding that practitioners need to deliver the FFTL vocabulary program in a targeted format. It introduces practitioners to understandings from research about the impact of a limited vocabulary on learning, and a multi strategy approach key to vocabulary instruction: a teaching sequence, learning activities, and instructional components such as the identification of words to target - Tier 2 words (Beck, McKeown and Kucan, 2013), example lesson plans, and use of planning and recording formats. 
The vocabulary program includes a lesson sequence - Revise, Teach, Practise, Apply - for use in the elementary/primary context. This sequence redistributes the elements included in Marzano's six step process for teaching vocabulary used in the high/secondary school context - explain, restate, show, refine, discuss, play (Marzano \& Pickering, 2005), also supported for effective vocabulary instruction by Stahl and Kapinus' (2001) research.

The students chosen for the project are identified by their teachers as having a limited or poor vocabulary. This is shown most clearly in their reading comprehension, which is weaker than their ability to decode words. Students are taught in groups of approximately four.

Vocabulary instruction involves an explicit introduction to the focus words, linking the unfamiliar word to words that they already knew, using it in examples which illustrate its meaning, repeating its pronunciation and meaning, as well as identifying words of a similar meaning and related words. After this introduction the word is handed over to the group for them to use and explore, often in the context of a cooperative learning activity such as a game or practical drama or speaking and listening activity. Finally, the group is asked to apply their knowledge, for example, by inventing sentences where the new word is used appropriately in context. This word is revisited and used again at the start of the next lesson and added to the store of words, often on display, which the students return to over the following lessons.

Teachers and teaching assistants taking part in this targeted vocabulary program deliver a $10-15$ minute lesson to small groups of 4 students aged 7 to 8 or 9 to 10 (Year 3 or Year 5 in primary schools in England), for approximately 20 weeks (over two terms). The lessons are delivered over a minimum of $3-4$ times per week with daily delivery being optimal. The aim is to introduce 5 new words, with additional words with a related meaning, each week.

The FFTL vocabulary program comprises:

a) advice on identifying students with limited vocabulary

b) an outline lesson sequence

c) advice on the selection of appropriate, 'tier 2' words to focus upon whether they are drawn from texts in use in the classroom, words from prescribed lists, work in other subjects or topic work, or words of general interest

d) a set of 'perspectives' from which to focus the initial teaching or introductory investigation of the new word. These perspectives include identifying the meaning and use(s) of the new word and linking it to a familiar known word, exploring clues contained in the spelling, e.g. prefixes and suffixes, the grammatical function of the word, etymological background and any other features which make the word memorable or distinctive. This approach is modelled during training and included in the teacher manual

e) advice on other important teacher strategies to support the handover of the new vocabulary for children to use. These include drama and speaking and listening strategies designed to help students develop confidence in using the new words and also a sense of appropriateness - when a word might and might not be used effectively

f) materials to support the students in using and exploring the newly introduced word. The resource box includes a set of games and activities which encourages 
students to handle the new words and reflect upon them afterwards, role cards, and a vocabulary journal for students to note their own progress and keep track of their developing understanding of vocabulary.

The vocabulary program is summarized in Table 1. The treatment group students receive the intervention, while the control group students continue with business as usual, comprising their normal literacy practices for students in Year 3 and Year 5.

\section{[INSERT TABLE 1 HERE]}

\section{Program Theory of Change (ToC)}

The logic model (Figure 1) describes the program components (Inputs, outputs, outcomes), including the theory of change, and how implementation factors relate to program outcomes. 
Figure 1 Vocabulary program logic model

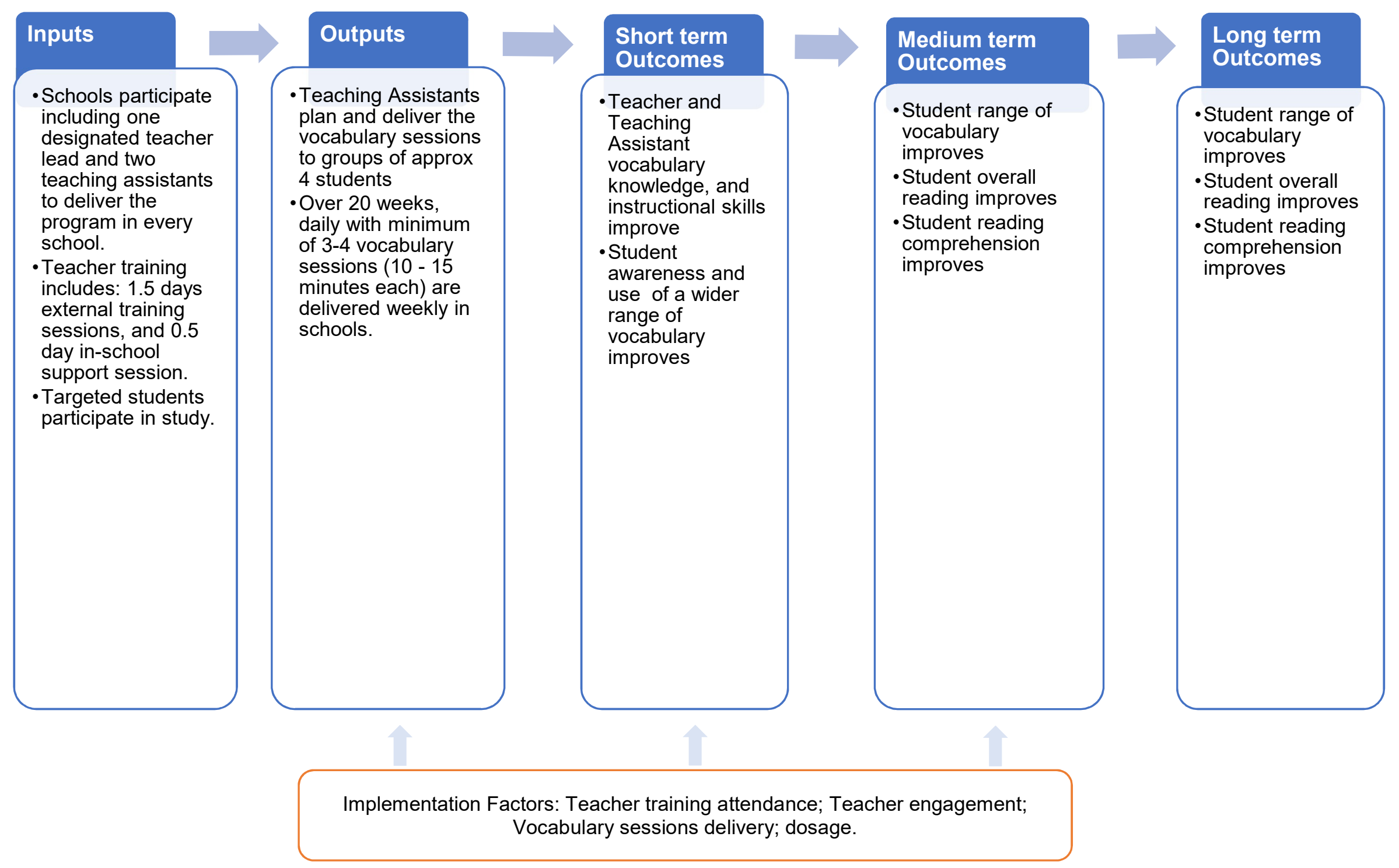




\subsection{Underpinning Theory of Intervention}

The underpinning Theory of Intervention is as follows. As shown in logic model (Figure 1), the overall aim of the vocabulary program is to increase the vocabulary of children, resulting in improved reading, including reading comprehension. In order to achieve these outcomes teacher training is necessary to improve teacher knowledge and change professional practice of vocabulary instruction, learn to scaffold student learning, and promote student collaboration during the learning process. Students need to be exposed to regular spaced instruction using the proposed multi-strategy vocabulary program.

It is accepted that there is limited intentional vocabulary instruction in the primary grades (Wanzek, 2014).The vocabulary program seeks to address this by improving teachers' awareness of vocabulary strategies and pedagogical methodologies and tools to implement in the classroom, based on evidence of effective practice. This aim is congruent with research which suggests that the size of a child's functional lexicon helps predict literacy outcomes (Moore and Hammond, 2014), and that pupil vocabulary skills can be enhanced through vocabulary teaching instruction, resulting in improved reading including reading comprehension (Beck and McKeown, 2007). Research modeling the comprehension process demonstrates the key role of vocabulary in reading for children in upper primary to secondary grades, with vocabulary and background knowledge being the greatest contributors to comprehension ability (Cromley and Azevedo, 2007). This view is congruent with Apthorp et al., (2012) who advocate targeting instruction in vocabulary as a direction for improving reading comprehension.

An important element of the vocabulary intervention is high quality professional development based on evidence-informed theory (Coe et al., 2014). In this case this includes distributed learning, scaffolded and cooperative learning, and learning using a multi-strategy approach to vocabulary instruction. The training for the vocabulary program is delivered through external training days where groups of teachers come together from different schools to learn together, combined with in-school support of teachers by program trainers. Teachers are trained on both how to deliver the program, and how to identify children who may have poor vocabulary and are poor comprehenders.

During vocabulary instruction therefore, teachers focus on implementing a multistrategy approach including: a teaching sequence; learning activities; and instructional components such as the identification of words to target - Tier 2 words (Beck, McKeown and Kucan, 2013). Example lesson plans are provided, and teachers learn to use planning and recording formats. Training and materials are based on the following underpinning theories and evidence:

The development of preliterate phonological abilities in children can be fostered by a strong lexical development (Walley, Metsala, \& Garlock, 2003). Hence the lexical restructuring hypothesis suggests that as young children acquire new vocabulary, their acoustic representations of words can be further refined, which enables phonological awareness and greater fluidity with regular word decoding (Metsala \& Walley, 1998), consolidated through emergent literacy experiences in children (Walley, Metsala, \& Garlock, 2003). Particularly pertinent for older elementary/primary age children, in line with the lexical quality hypothesis, becoming a proficient reader requires having high 
quality lexical representations (Perfetti, 2007), and these develop by multiple exposures to words (Perfetti \& Hart, 2002). A direct effect can be expected of semantics on word reading because a better semantic quality of lexical representations may facilitate word identification (Perfetti \& Hart, 2002).

Stahl and Fairbanks (1986) summarize results from 41 studies, reporting an average effect size of 0.91 , an effect size which would theoretically raise the comprehension of an average child from the 50th percentile to the $83^{\text {rd }}$ percentile. More recently, metaanalyses confirm the effectiveness of vocabulary instruction for improving vocabulary ability (ES+0.29 to 1.21) and reading comprehension (ES+0.10 to 0.50$)$ (Elleman, Lindo, Morphy \& Compton, 2009; Marulis \& Newman, 2010). Researchers advocate sustained targeted vocabulary interventions are required to make a substantial impact (Beck \& McKeown, 2007; Biemiller, 2003), particularly for children from socioeconomically disadvantaged backgrounds (Hart \& Risley, 1995).

The vocabulary program is underpinned by the theories of distributed learning and scaffolded learning in small groups using cooperative learning approaches which enhance meta-cognition, and a multi-strategy approach to teaching vocabulary, particularly Tier 2 words (those which characterize written language, rather than everyday spoken language):

Metacognitive skills develop when children are aged five to six and increase rapidly from the age of eight (Veenman, 2016). Skills are demonstrated through young children's emerging awareness of their memory (metamemory) and self-monitoring of understanding. Development of these skills is crucial in fostering independent learning and enables children to become active learners. A review of the impact of metacognitive strategies by the Education Endowment Foundation (EEF) suggests it has positive effects (ES+0.7) and that metacognitive development is most effective when instruction involves adult scaffolding and collaborative group work (Higgins, Katsipataki, Kokotsaki, Coleman, Major, \& Coe, 2014).

Distributed learning or spaced learning which stem from the psychology and neuroscience literature, where two or more study periods are separated in time by an inter-study interval, has been hypothesized to have a greater impact on learning outcomes than block learning (Rea \& Modigliani, 1985, 1987; Seabrook, Gordon, Brown \& Solity, 2005; Solity \& Vousden, 2009). This underpins the delivery structure of the vocabulary program where students engage in the program for approximately 15-20 minutes 3-5 times weekly.

The need for scaffolding during the modelling process in the vocabulary program is underpinned by Vygotsky's theory (1978) of learning within the 'zone of proximal development' which requires mediation and carefully directed support, which also includes structured delivery in small groups of approximately four children working together with teacher support to make this scaffolded learning possible. This approach is in line with research which suggests scaffolding is effective (Van de Pol, Volman \& Beishuizen, 2010).

The interactions that take place between members of the group during the vocabulary learning activities enable cooperative construction of meaning whilst learning new vocabulary. Cooperative learning can be defined as a learning situation in which two 
or more students learn together to achieve a common goal or solve the task at hand, commonly through peer directed interactions where learners actively participate in group activities, while teachers usually serve as facilitators. Research shows that cooperative learning can work well for all ages if activities are suitably structured for learners' capabilities, and positive evidence has been found across the curriculum. Theories underpinning social interaction during cooperative learning have been substantively developed and described by Social Interdependence Theory (Johnson, Johnson \& Roseth, 2010; Johnson \& Johnson 2012). A meta-analysis undertaken some years ago by Johnson, Johnson \& Stanne (2000) finds positive effects (ES +0.19 - +0.91) and more recently the Education Endowment Foundation toolkit recommends collaborative learning as a very low-cost approach with moderate impact $(E S+0.5)$ based on extensive evidence.

The multiple strategy approach to vocabulary instruction proposed here is aligned to the lexical quality hypothesis, which suggests that becoming a proficient reader requires having high quality lexical representations (Perfetti, 2007), and that these develop by multiple exposures to words (Perfetti \& Hart, 2002). Implementing multiple encounters and active processing of target words in vocabulary instruction can lead to comprehension gains (Apthorpe et al, 2012). Vocabulary instruction which provides learners with information about both the definition and context of target words, as well as varied multiple encounters with these words and active processing of them can be beneficial to children's reading (Beck, McKeown, \& Kucan, 2002). Stahl and Kapinus (2001) support such a range of approaches used together in vocabulary instruction as most effective, including: helping children gain ownership of words (being able to use or think about a word in a variety of different ways); providing multiple exposures through rich and varied activities to meaningful information about the word; instruction which includes both definitional and contextual information about each word's meaning and which involves children more actively in word learning.

Such a multi-strategy approach to vocabulary development is hypothesized to improve vocabulary skills and to have an impact on reading ability and reading comprehension outcomes. The impact of the vocabulary program on reading abilities of students will be investigated using an online standardized reading measure.

\subsection{Theory of Change}

Figure 1 also illustrates the ToC. It is proposed that by providing a structured vocabulary program and appropriate training to teachers and teaching assistants, that the processes underpinning the teaching of vocabulary can be changed. This assumes that the training will impact on the professional action of teachers and teaching assistants, resulting in use of alternative pedagogies. As a result, it is projected that pupil use of approaches to vocabulary learning to improve their vocabulary skills and knowledge of words will lead to improved reading.

Teacher surveys and attendance at training, in addition to vocabulary instruction dosage will be analyzed as implementation factors/mediators for outcome change.

3.3 Criteria for recommendation that the vocabulary program is ready for a Stage 3 Definitive RCT 
The following criteria were developed to determine whether the vocabulary program is ready for a Stage 3 Definitive RCT:

- That professional development in use of the vocabulary program is able to be delivered in line with specification to elementary/primary school teachers

- That the vocabulary program is able to be delivered in line with specification to students in elementary/primary school

- That school teachers/teaching assistants evaluate their use of the vocabulary program positively enough to conclude that it could be scaled up

- That use of the vocabulary program, when compared to a control group not using the technique, can result in a positive effect size for students using the technique.

\section{Research Plan}

Research questions

The vocabulary program study will be a Level 2 efficacy/exploratory trial (randomized at the individual pupil level, using block randomization to ensure even numbers of intervention and control students in each arm of the trial within each of the 7 schools) complemented by a process evaluation. The study will primarily look at the effect of the vocabulary program on the reading ability of children in primary schools. Pre and post-test measures of 101 children in 7 schools will assess the efficacy of the vocabulary program in optimal conditions on a small scale.

The study will address the following questions:

a) Can the program be delivered in primary schools?

b) What is the impact of the vocabulary program on children's reading ability?

c) Does the impact of the program differ significantly according to variations in implementation fidelity? (Process evaluation)

d) Is the program scalable?

Answers to the above questions will inform decisions as to whether the program is ready to be scaled to an effectiveness trial.

\section{Design summary of the randomized controlled trial (RCT) and process evaluation}

5.1 Logic Model: A logic model has been developed for the vocabulary program intervention (Fig. 1). The logic model will help guide the process evaluation and enable us to interpret the findings of the RCT. The SPIRIT guidelines have been consulted to help structure the protocol for this trial (SPIRIT, 2015).

5.2 RCT Evaluation: The main outcomes will be evaluated using ANCOVA analysis. The RCT will test for changes in children's reading abilities. Any changes in the intervention group receiving the 20 -week vocabulary program will be measured against the control group who do not receive the treatment. It is calculated that the sample is large enough to detect a significant Effect Size of 0.2 , with p $>0.05$, and $80 \%$ power (Soper, 2019). Results will also be presented as Effect Sizes and Cohen's $d$ 
will be calculated for each of the main outcome measures.

5.3 Process evaluation: A process evaluation will supplement the RCT to measure the fidelity to implementation of the program. Guided by the MRC Framework (Moore, Audrey, Barker, Bond, Bonell, Hardeman, Moore, O'Cathcain, Tinati, Wight \& Bair, $2015)$ the process evaluation will seek to assess whether the vocabulary training was attended, teacher engagement, and dosage of implementation. To help assess this, the trainer will provide naturally occurring training attendance data, and teacher leads and teaching assistants will complete a post-program digital perception survey, including questions about learning for the control group during the program.

\section{Assessment procedures}

All children in both intervention and control groups will be tested before and after the intervention. Schools will be provided by the trainers with guidance to select upto 16 children from years 3 and 5 combined (aged 7 to 8 or 9 to 10), who are good decoders but poor comprehenders.

\subsection{Pre-test measures}

The selected children, upto 8 from years 3 and 5 respectively, will be tested prior to teacher training and program intervention.

- Reading pre-test: The selected children from each school will complete an online standardized reading test, the New Group Reading Test (digital version) from GLAssessment. This is an adaptive test which has high reliability (Alpha values 0.9 ) (GL-Assessment, 2018). All children will be tested in exam conditions by schools prior to teacher training and program intervention. These will assess children's reading ability, including sentence completion and reading comprehension.

\subsection{Post-test measures}

These will be repeated with all treatment and control children 20 weeks after the program has started. This will include the following tests:

- Reading post-test: The selected children from each school will complete an online standardized reading test, the New Group Reading Test (NGRT) (digital version) from GL-Assessment. This is an adaptive test which has high reliability (Alpha values 0.9) (GL-Assessment, 2018). All children will be tested in exam conditions by schools prior to teacher training and program intervention. These will assess children's reading ability, including sentence completion and reading comprehension.

The differential effects of the program on children's reading attainment level will be determined using the post test data obtained from the NGRT test. The NGRT has two sub-scales, sentence completion and passage comprehension. These combine to give an overall reading score. Analysis will be undertaken on both sub-scales and the combined overall reading score.

\subsection{Dosage record:}

A 20-week teacher implementation session delivery plan (recommended daily sessions with a minimum of 3 weekly sessions of 15 minutes each) will be used by 
teachers to record weekly delivery data and will be collected at post-test to help measure the program's implementation fidelity.

\subsection{Teacher questionnaire at post-test}

The teachers and teaching assistants will be asked to fill in a questionnaire at posttest for their feedback regarding the vocabulary program and the implementation process. All questionnaires will be completed online using Lime Survey. The teacher questionnaire will consist of 19 questions to include 11 questions measured on a 4point scale ranging from 'strongly agree' to 'strongly disagree'. In addition, the questionnaire will include 5 open questions and three closed questions with menu of options about session delivery.

6.5 Training delivery naturally occurring data: training attendance.

Training attendance records will be collected by FFTL program trainers.

Instruments and measures are summarized in Table 2.

\section{[INSERT TABLE 2 HERE]}

\section{Sample}

101 students in Years 3 and 5 (students aged 7-8 and 9-10 years), from 7 schools in the North East of England will be recruited to the trial. The trial will recruit upto 8 students from year group (upto 4 to act as intervention and upto 4 to act as control) across 2 year groups, upto 16 from each school. Students are eligible to take part in this trial if the school selects them as being good decoders but poor comprehenders, using the guidance provided to them. This sample size would be large enough to detect an Effect Size of +0.33 at $80 \%$ power assuming even distribution of sample between control and intervention groups, pre-test scores are used as a covariate in ANCOVA and loss of sample due to attrition is $<5 \%$. We consider an effect size of +0.33 to be reasonable based on evidence from experimental studies using vocabulary instruction where the average effect sizes range from +0.29 to +1.21 for the impact on vocabulary and +0.10 to +0.50 for the impact on comprehension (Elleman et al., 2009; Marulis \& Newman, 2010).

\section{Randomization}

Students will be individually randomized to condition. This will be undertaken by listing the students alphabetically within their year group and school. A random number generator (Random Number Generator for iPhone version 5.0 by Nicolas Dean) will be used to generate a whole number between 0 (control) and 1 (vocabulary intervention). Once the first student from a year group is assigned to condition the other 7 students are randomized sequentially to condition in Year 3 and Year 5 respectively. This will ensure even numbers of intervention and control students in each arm of the trial. This will use true randomization and no minimization will be used.

\section{Sample size calculation and analysis}

The primary outcome will be to establish Effect Sizes of the intervention. In line with MRC (2019) exploratory trials, Effects Sizes and 95\% confidence intervals will be 
presented. However, ANCOVA will also be undertaken on the data. This is appropriate as individual randomisation will take place within classes, reducing clustering effects in the data. Missing data will be treated as missing at random if levels remain under $5 \%$. However, if levels increase above $5 \%$ then analyses will be undertaken to explore patterns in the missing data and multiple imputation of missing variables will be considered.

\section{Personnel}

- Professor Allen Thurston, Queen's University Belfast \& Zhengzhou University

- Dr Maria Cockerill, Queens University Belfast

- Andy Taylor, Fischer Family Trust Literacy (program developer and trainer)

\section{Timescales}

The planned timescale for the research is 12 months. Table 3 below outlines a summary of the key milestones.

\section{[INSERT TABLE 3 HERE]}

\section{Cost}

The cost of implementing the program will include resources and personnel time spent on delivering the program with follow up support. The cost of the vocabulary program implementation will be estimated per pupil over a one-year period and will include: Teacher training 1.5 days (external sessions); teacher in-school support session 0.5 days; teacher manual, and vocabulary instruction resources for session delivery.

\section{Ethics}

The trial was approved through two ethics procedures. The intervention of the trial and testing was approved by the Headteachers who took part in the trial. The subsequent matching, combining and analysis of data was approved by [Removed for review].

\section{References}

Apthorp. H, Randel, B., Cherasaro, T., Clark, T., McKeown, M., \& Beck, I. (2012) Effects of a Supplemental Vocabulary Program on Word Knowledge and Passage Comprehension, Journal of Research on Educational Effectiveness, 5:2,160-188, DOI: $10.1080 / 19345747.2012 .660240$

Beals, D. (1997) Sources of support for learning words in conversation: evidence from mealtimes. Child Language, 24:673-694.

Beck, I., \& McKeown, M. (2007) Increasing your low income children's oral vocabulary repertoires through rich and focused instruction. The Elementary School Journal Vol 107 , No 3 
Beck, I. L., McKeown, M. G., \& Kucan, L. (2002) Bringing words to life: Robust vocabulary instruction. New York, NY: Guilford.

Beck, I., McKeown, M., \& Kucan, L. (2013) Bringing Words to Life, Second Edition: Robust Vocabulary Instruction

Becker, W.C. (1977) Teaching reading and language to the disadvantaged - what we have learned from field research. Harvard Educational Review, 47:518-543.

Biemiller, A. (2003) Vocabulary: needed if more children are to read well. Reading Psychology, 24:323-335.

Chall, J.S., Jacobs, V.A. \& Baldwin, L.E. (1990) The reading crisis: why poor children fall behind. Cambridge, Massachusetts: Harvard University Press.

Coe, R., Aloisi, C., Higgins, S., \& Elliot Major, L. (2014). What makes great teaching? Review of the underpinning research https://www.suttontrust.com/wpcontent/uploads/2014/10/What-Makes-Great-Teaching-REPORT.pdf.

Cromley, J. G., \& Azevedo, R. (2007). Testing and refining the direct and inferential mediation model of reading comprehension. Journal of Educational Psychology, 99, 311-325.

Cunningham, A.E. \& Stanovich, K.E. (1997) Early reading acquisition and its relation to reading experience and ability 10 years later. Developmental Psychology, 33:934945

Duke, N. \& Moses, A. (2003) 10 research tested ways to build children's vocabulary. New York, NY: Scholastic Inc.

Elleman, A., Lindo, E., Morphy, P., \& Compton, D. (2009). The impact of vocabulary instruction on passage-level comprehension of school-age children: A meta-analysis. Journal of Research on Educational Effectiveness, 2, 1-44.

Fisher, P. \& Blachnowicz, C. (2005) Vocabulary instruction in a remedial setting. Reading and Writing Quarterly, 21:281-300.

Hart, B., \& Risley, T. R. (1995). Meaningful differences in the everyday experience of young American children. Baltimore, MD: Brookes.

Higgins, S., Katsipataki, M., Kokotsaki, D., Coleman, R., Major, L.E., and Coe, R. (2014). The Sutton Trust-Education Endowment Foundation Teaching and Learning Toolkit. London: Education Endowment Foundation.

Hoffmann, T., Glasziou, P., Boutron, I., Milne, R., Perera, R., Moher, D., Altman, D., Barbour, V., Macdonald, H., Johnston, M., Lamb, S., Dixon-Woods, M., McCulloch, P., Wyatt, J., Chan, A., \& Michie, S. (2014). Better reporting of interventions: Template for intervention description and replication (TIDieR) checklist and guide. BMJ, 348, g1687 Retrieved from: http://www.bmj.com/content/348/bmj.g1687 (31st July, 2019). 
Johnson, D.W., and Johnson, R.T. (2012). Restorative Justice in the Classroom: Necessary Roles of Cooperative Context, Constructive Conflict, and Civic Values. Negotiation and Conflict Management Research, 5, (1), 4-28.

Johnson, D.W., Johnson, R.T., and Roseth, C. (2010). Cooperative learning in middle schools: interrelationship of relationships and achievement. Middle Grades Research Journal, 5(1), 1-18.

Johnson, D. W., Johnson, R. T., and Stanne, M B. (2000). Cooperative learning methods: A metaanalysis. Minneapolis: University of Minnesota.

Marulis, L. M., \& Newman, S. B. (2010). The effects of vocabulary intervention on young children's word learning: A meta-analysis. Review of Educational Research, 80, 300-335.

Marzano, R., \& Pickering D. (2005) Building Academic Vocabulary: Teacher's Manual. ASCD; Teacher's Manual ed. Edition.

Medical Research Council (2019) Developing and evaluating complex interventions: Following considerable development in the field since 2006, MRC and NIHR have jointly commissioned an update of this guidance to be published in 2019. Retrieved from: https://mrc.ukri.org/documents/pdf/complex-interventions-guidance/ (6 November 2019).

Metsala, J.L. \& Walley, A.C. (1998). Spoken vocabulary growth and the segmental restruc- turing of lexical representations: Precursors to phonemic awareness and early reading ability. In J.L. Metsala \& L.C. Ehri (Eds.), Word recognition in beginning literacy (pp. 89-120). Mahwah, New Jersey: Erlbaum.

Moore, G. F., Audrey, S., Barker, M., Bond, L., Bonell, C., Hardeman, W., Moore, L., O'Cathain, A., Tinati, T., Wight, D., \& Baird, J. (2015). Process evaluation of complex interventions: Medical Research Council guidance. BMJ, 350, 1258. doi: https://doi.org/10.1136/bmj.h1258

Moore, W., Hammond, L., \& Fetherston, T. (2014) Strengthening vocabulary for literacy: an analysis of the use of explicit instruction techniques to improve word learning from story book read-alouds, Australian Journal of Learning Difficulties, 19:2, 153-172, DOI:10.1080/19404158.2014.964992

National Reading Panel (2000) Teaching Children to Read: and evidence-based assessment of the scientific research literature on reading and its implications for reading instruction. Reports of subgroups. NICHD. https://www.nichd.nih.gov/sites/default/files/publications/pubs/nrp/Documents/report. pdf (21 Aug 2019).

Perfetti, C. (2007). Reading ability: Lexical quality to comprehension. Scientific Studies of Reading, 11, 357-383. 
Perfetti, C. A., \& Hart, L. (2002). The lexial quality hypothesis, in precursors of functional literacy. In L. Verhoeve, C. Elbro, \& R. Pieter (Eds.). Study in written language and literacy 11 (pp. 189-213). John Benjamins Publishing Company.

Rea, C. P., \& Modigliani, V. (1985). The effect of expanded versus massed practice on the retention of multiplication facts and spelling lists. Human Learning, 4, 11-18.

Rea, C. P., \& Modigliani, V. (1987). The spacing effect in 4- to 9-year-old children. Memory \& Cognition, 15, 436-443.

Seabrook, R., Gordon, D., Brown, A., \& Solity, J. (2005). Distributed and massed practice: From laboratory to classroom. Applied Cognitive Psychology, 19, 107-122. Onlinelibrary.wiley.com.

Solity, J., \& Vousden, J. (2009). Real books vs reading schemes: a new perspective from instructional psychology. Educational Psychology, 29(4), 469-4511. https://doi.org/10.1080/01443410903103657 Taylor and Francis online.

Soper, D. (2019). A-priori sample size calculator for multiple regression. Retrieved from: https://www.danielsoper.com/statcalc/calculator.aspx?id=1 (31 Jan 2019).

SPIRIT (2015). SPIRIT [ONLINE]. Available at: http://www.spirit-statement.org/spiritstatement/. Retrieved $31^{\text {st }}$ July 2019.

Stahl, S., \& Fairbanks, M.M. (1986) The effects of vocabulary instruction: a model based meta-analysis. Review of Educational Research,56:72-110.

Stahl, S.A., \& Kapinus, B. (2001). Word power: What every educator needs to know about teaching vocabulary. Washington, D.C.: National Education Association.

Van de Pol, J., Volman, M., \& Beishuizen, J. (2010). Scaffolding in teacher-Student interaction: A decade of research. Educational Psychology Review, 22, 271-296.

Veenman, M. V. (2016). Metacognition, in Afflerbach, P. (Ed.). Handbook of individual differences in reading: Reader, text, and context. New York: Routledge.

Verhoeven L., van Leeuwe, J., \& Vermeer, A. (2011) Vocabulary Growth and Reading Development across the Elementary School Years, Scientific Studies of Reading, 15:1, 8-25, DOI: 10.1080/10888438.2011.536125

Vygotsky, L. S. (1978). Mind in society: The development of higher psychological processes. Cambridge M.A: Harvard University Press.

Waldfogel, J. \& Washbrook, E. (2010) Low income and early cognitive development in the U.K.: A report for the Sutton Trust. https://www.suttontrust.com/wpcontent/uploads/2010/02/Sutton Trust Cognitive Report-2.pdf (21 Aug 2019).

Walley, A. C., Metsala, J. L., \& Garlock, V. M. (2003). Spoken vocabulary growth: Its role in the development of phoneme awareness and early reading ability. Reading and Writing, 16, 5-20. doi:10.1023/a:1021789804977 
Wanzek, J. (2014). Building word knowledge: Opportunities for direct vocabulary instruction in general education for students with reading difficulties. Reading \& Writing Quarterly, 30, 139-164. https://doi.org/10.1080/10573569.2013.789786

\section{Competing Interests Statement}

The authors have no competing interests to declare.

Table 1: Vocabulary Program TIDieR checklist (Hoffmann, Glasziou, Boutron, Milne, Perera, Moher, Altman, Barbour, Macdonald, Johnston, Lamb, Dixon-Wodds, McCulloch, Wyatt, Chan, \& Michie, 2014).

\begin{tabular}{|l|l|}
\hline ITEM No. & Item \\
\hline Brief Name & Vocabulary program (Targeted intervention) \\
\hline a & $\begin{array}{l}\text { Training program for teachers aimed at improving vocabulary ability and reading } \\
\text { of students aged 7 to 10 years }\end{array}$ \\
\hline Why & $\begin{array}{l}\text { Materials: A teacher training program delivered by the [Removed for Review] } \\
\text { which includes external school training (for teachers and teaching assistants) } \\
\text { interspersed with internal follow up support/training. } \\
\text { Resources: including teacher manual, diagnostic tool, and teaching resource box. }\end{array}$ \\
\hline What & $\begin{array}{l}\text { Procedures: External school training for the vocabulary program teacher lead, } \\
\text { and designated teaching assistants. Internal follow up training/support sessions } \\
\text { to support a balanced instructional approach to vocabulary teaching. }\end{array}$ \\
\hline d & $\begin{array}{l}\text { Vocabulary trainer provides teacher and teaching assistant internal and external } \\
\text { training. Teachers and teaching assistants provide instructional activities to } \\
\text { students based on their training }\end{array}$ \\
\hline Who Provided & Initial training sessions provided to groups of teachers \\
\hline e & $\begin{array}{l}\text { External training provided out of school setting. Internal training provided in school } \\
\text { setting including classroom. }\end{array}$ \\
\hline How & how \\
\hline Where & $\begin{array}{l}\text { There are two external training sessions and one internal follow up session over } \\
\text { the } 20 \text { week period. Teachers are utilizing their training over the course of the } \\
\text { program. }\end{array}$ \\
\hline g & $\begin{array}{l}\text { The program logic model was not changed during the research and is included in } \\
\text { Figure 1. }\end{array}$ \\
\hline When and \\
much
\end{tabular}


Table 2: Measurement tools

\begin{tabular}{|l|l|l|l|}
\hline Outcome & Instrument & Completed by & Alpha values \\
\hline $\begin{array}{l}\text { Reading } \\
\text { Comprehension }\end{array}$ & $\begin{array}{l}\text { New Group Reading Test } \\
-\quad \text { Passage } \\
\text { Comprehension subtest }\end{array}$ & Pupil & $\begin{array}{l}>0.9 \\
\text { Assessment, } \\
2018)\end{array}$ \\
\hline Overall reading & New Group Reading Test & Pupil & $\begin{array}{l}>0.9 \\
\text { Assessment, } \\
2018)\end{array}$ \\
\hline Reading accuracy & $\begin{array}{l}\text { New Group Reading Test } \\
- \text { Sentence completion } \\
\text { subtest }\end{array}$ & Pupil & $\begin{array}{l}\text { Assessment, } \\
2018)\end{array}$ \\
\hline $\begin{array}{l}\text { Implementation } \\
\text { factors }\end{array}$ & & & \\
\hline $\begin{array}{l}\text { Dosage } \\
\text { Teacher } \\
\text { engagement }\end{array}$ & $\begin{array}{l}\text { 20-week implementation } \\
(60-100 \text { minutes weekly) }\end{array}$ & Teacher & n/a \\
\hline $\begin{array}{l}\text { Teacher } \\
\text { engagement }\end{array}$ & Training attendance & Trainer & $\mathrm{n} / \mathrm{a}$ \\
\hline
\end{tabular}

\section{Table 3. Gannt Chart of timescales}

\begin{tabular}{|l|l|l|l|l|l|l|l|l|l|l|l|l|}
\hline Activities & Mth 1 & Mth 2 & Mth 3 & Mth 4 & Mth 5 & Mth 6 & Mth 7 & Mth 8 & Mth 9 & Mth 10 & Mth 11 & Mth 12 \\
\hline $\begin{array}{l}\text { Develop } \\
\text { logic model }\end{array}$ & & & & & & & & & & & & \\
\hline $\begin{array}{l}\text { Recruit } \\
\text { schools }\end{array}$ & & & & & & & & & & & & \\
\hline $\begin{array}{l}\text { NGRT } \\
\text { pretest data }\end{array}$ & & & & & & & & & & & & \\
\hline $\begin{array}{l}\text { Develop } \\
\text { survey } \\
\text { measures }\end{array}$ & & & & & & & & & & & & \\
\hline $\begin{array}{l}\text { Training day } \\
1 \text { (1.0) }\end{array}$ & & & & & & & & & & & & \\
\hline $\begin{array}{l}\text { Program } \\
\text { delivery } \\
\text { in schools }\end{array}$ & & & & & & & & & & & & \\
\hline $\begin{array}{l}\text { Training day } \\
2 \text { (0.5) }\end{array}$ & & & & & & & & & & & & \\
\hline $\begin{array}{l}\text { In-school } \\
\text { support visit }\end{array}$ & & & & & & & & & & & & \\
\hline $\begin{array}{l}\text { NGRT post } \\
\text { test }\end{array}$ & & & & & & & & & & & & \\
\hline $\begin{array}{l}\text { Teacher } \\
\text { survey }\end{array}$ & & & & & & & & & & & & \\
\hline $\begin{array}{l}\text { Session } \\
\text { delivery data }\end{array}$ & & & & & & & & & & & & \\
\hline $\begin{array}{l}\text { Analysis of } \\
\text { data }\end{array}$ & & & & & & & & & & & & \\
\hline $\begin{array}{l}\text { Write-up to } \\
\text { include } \\
\text { process } \\
\text { evaluation }\end{array}$ & & & & & & & & & & & & \\
\hline Final report & & & & & & & & & & & & \\
\hline
\end{tabular}

